\title{
DẪN LIỆ MỚI VỀ MÔI TRƯỜNG NƯỚC VÀ SINH VẬT TRONG CÁC HANG NGÂM VÀ HỔ NƯỚC MẶN KHU VỰC VỊNH HẠ LONG, CÁT BÀ
}

\section{Nguyễn Đăng Ngải", Đậu Văn Thảo, Đỗ Công Thung, Lê Thị Thúy, Phạm Văn Lượng, Cao Thu Trang, Vũ Thị Lụu, Đàm Đức Tiển, Nguyễn Văn Quân, Phạm Văn Chiến}

Viện Tài nguyên và Môi truờng biển-Viện Hàn lâm Khoa học và Công nghệ Việt Nam *E-mail: ngaind@imer.ac.vn

Ngày nhận bài: 28-10-2015

TÓM TĂT: Hang ngầm và hồ nước mặn là 2 dạng sinh cảnh khá phổ biến ở Hạ Long và Cát Bà, do nhiều nguyên nhân khác nhau đến nay chúng rất it được quan tâm nghiên cứu. Các kết quả nghiên cứu bước đầu về môi trương và quần xã sinh vật trong 3 hang ngầm (Hang Sáng, Hang Tối, Hang Quả Bàng) và 3 hồ nuớc mặn (Áng Đầu Bê, Áng Dù, Áng Quả Bàng) cho thấy: Môi truờng nước có sư khác biệt giữa các hồ, đặc biệt là trong hồ kín nhu Áng Dù có độ muối thấp (9\%o), trong khi các hồ có cưa thông với biển có độ muối gần tương đương với môi truờng ngoài (23-27\%o). Hàm lượng chất khí hòa tan nhu DO trong các hồ nước mặn khá cao tù 7,63 - 9,03 mg/l, cao hơn trong hang ngầm và cao hơn ở môi truờng biển xung quanh. Các yếu tố vật lý và hóa học trong môi trường nước tại các hang ngầm gần tuơng đương với môi truờng bên ngoài do có các hang ngầm đều thông với biển và có nước chảy thuờng xuyên theo sự lên xuống của thủy triều. Quần xã sinh vật trong các hang khá phong phú với trên 142 loài được tìm thấy, phổ biến nhất là hải miên và san hô mềm, chúng phân bố dọc chiều dài hang. Có một số loài có giá trị kinh tế cao thường gặp trong hang là Cù kì Myomenippe hardwickii, ghe Portunus pelagicus, ốc nón Trochus pyramis, cá dìa Siganus sutor, cá hồng Lutjanus russellii ... Chưa phát hiện thấy các loài chuyên biệt sống cố định trong hang. Ở các hồ nước lưu thông với môi truờng bên ngoài có sư xuất hiện của rạn san hô, chúng tạo thành một dải hẹp bao quanh hồ. Các bãi cát thuờng xuất hiện quanh hồ ở độ sâu 0,5 $2 m$ có các loài đặc sản nhu phi phi, tu hài, hải sâm với mật độ khá cao (Áng Đầu Bêe, Áng Quả Bàng). Trong áng kín không có rạn san hô do nuoóc có độ muối thấp, có sư phân tầng của nhiệt độ và độ muối làm cho nhiệt độ ở tầng mặt thấp hơn tầng đáy $3-6^{0} C$ đây là hiện tuợng bất thuờng ở các hồ này.

Tù khóa: Hang ngầm, hồ nước mặn, đa dạng sinh học, môi trương.

\section{MỞ ĐẦU}

Sự hình thành địa chất, địa mạo ở khu vực Hạ Long, Cát Bà đã trải qua rất nhiều quá trình sụt chìm, biển tiến và tạo núi - biển thoái, sự thay đổi nâng lên hạ xuống của các mảng kiến tạo và sự xâm thực karst kéo dài khoảng 20 triệu năm qua đã hình thành nên các hang ngầm và hồ nước mặn khi khu vực bị ngập chìm do biển dâng [1]. Mặc dù hai kiểu sinh cảnh này khá phổ biến ở khu vực song do thiếu các thiết bị và kinh nghiệm nghiên cứu nên tới năm 2003 các nhà khoa học của Viện Tài nguyên và Môi trường biển và Italia trong dự án hợp tác về bảo tồn đa dạng sinh học ven biển Việt Nam đã khảo sát một số hồ nước mặn và hang nửa ngầm. Các nghiên cứu mới tập trung vào nhóm hải miên, còn các nhóm sinh vật khác ít được 
quan tâm. Các kết quả nghiên cứu được công bố bởi Cerrano và nnk., (2006) [2] và Azzini và nnk., (2007) [3] đã ghi nhận được 63 loài hải miên (sponge) ở toàn khu vực vịnh Hạ Long và Cát Bà, trong đó bao gồm cả trong các hồ nước mặn và hang ngầm. Từ đó đến nay chưa có nghiên cứu nào về môi trường cũng như sinh vật trong các kiểu sinh cảnh này.

Trong năm 2014, chúng tôi đã tiến hành nghiên cứu các điều kiện môi trường và sinh vật tại 3 hang ngầm là Hang Tối, Hang Sáng, Hang Quả Bàng và 3 hồ nước mặn là Âng Dù, Áng Đầu Bê, Âng Quả Bàng. Đây là những dữ liệu mới về môi trường và sinh vật bổ sung vào dữ liệu về hang ngầm và hồ nước mặn ở Việt Nam nói chung và khu vực Hạ Long, Cát Bà nói riêng.

\section{PHƯƠNG PHÁP NGHIÊN CÚU}

\section{Thời gian và địa điểm khảo sát}

Mẫu vật và số liệu khảo sát được tiến hành thu thập tại 3 hang ngầm là Hang Tối, Hang Sáng, Hang Quả Bàng và 3 hồ nước mặn là Áng Dù, Âng Đầu Bê, Áng Quả Bàng vào tháng 7 năm 2014 theo hình 1.

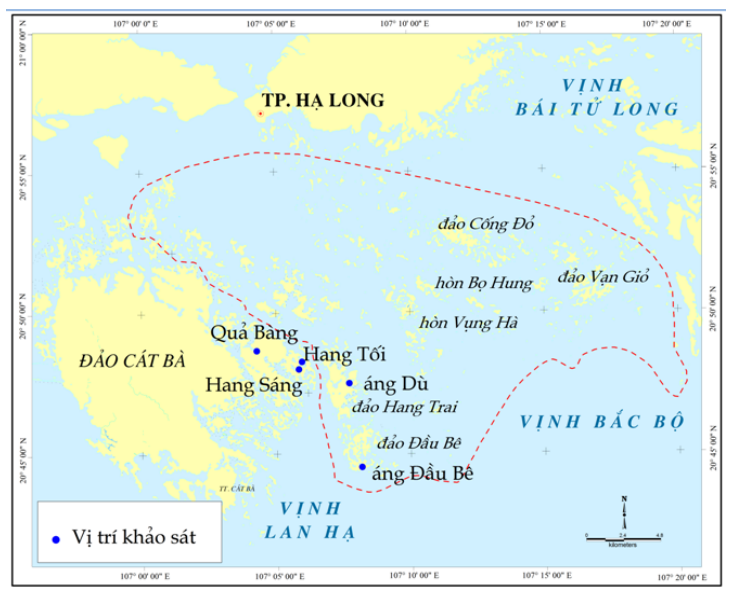

Hình 1. Vị trí khảo sát tại các hang ngầm và hồ nước mặn

\section{Phương pháp nghiên cứu}

\section{Phương pháp nghiên cúu chất lự̛ng môi trường}

Mẫu nước biển được lấy ở tầng mặt và tầng đáy bằng thiết bị lấy mẫu Niskin model 1010 .
Các thông số nhiệt độ, độ muối, DO, pH, độ trong được đo tại hiện trường bằng các máy đo:

Nồng độ oxy hoà tan (DO) và nhiệt độ nước được do bằng máy đo DO YSY 55;

Độ muối đo bằng khúc xạ kế cầm tay;

$\mathrm{pH}$ đo bằng máy đo $\mathrm{pH} \mathrm{OKATON}$;

Độ trong được đo bằng đĩa Shechi.

Các mẫu dinh dưỡng, $\mathrm{BOD}_{5}, \mathrm{COD}$ được thu, cố định và bảo quản theo quy trình $\mathrm{QA} / \mathrm{QC}$ và được phân tích trong phòng thí nghiệm.

\section{Phưong pháp nghiên cứu các nhóm sinh vật}

Động vật đáy: Áp dụng phương pháp thu mẫu động vật đáy vùng triều và dưới triều để nghiên cứu trong hồ nước mặn và hang ngầm.

Vùng triều: thu mẫu theo phương pháp Gurjanova (1972) [4], mẫu động vật đáy thu theo chiều thẳng đứng từ khu cao triều tới trung triều và thấp triểu. Thu mẫu định lượng trên các ô tiêu chuẩn $40 \times 40 \mathrm{~cm}$.

Vùng dưới triều: Mẫu thu thập theo phương pháp của English (1997) [5], sử dụng cuốc Ponar-Dredge có miệng mở diện tích bằng $0,05 \mathrm{~m}^{2}$. Trên vùng rạn san hô và hang ngầm thu mẫu định tính và định lượng bằng thiêt bị lặn Scuba.

Phân tích và xử lý mẫu: Mẫu động vật đáy được tách thành các nhóm nhỏ (thân mềm, giáp xác, da gai ...), bảo quản bằng cồn $70 \%$ và phân loại đến đơn vị taxon nhỏ nhất bằng phương pháp hình thái [4, 6-23].

San hô, hải miên và rong biển: sử dụng thiết bị lặn Scuba để tiến hành khảo sát và thu mẫu theo phương pháp của English (1997) [5], mẫu được phân loại đến đơn vị taxon nhỏ nhất bằng phương pháp hình thái: san hô [24-30], rong biển [31, 32], hải miên [33, 34].

Cá biển: Sử dụng thiết bị lặn Scuba để khảo sát cá theo phương pháp của English (1997) [5], dùng lưới, vợt, máy ảnh dưới để thu mẫu và chụp ảnh các loài cá bắt gặp trong quá trình khảo sát. Phân loại các mấu thu được theo phương pháp hình thái đến đơn vị taxon nhỏ nhất [35-38].

\section{KẾT QUẢ NGHIÊN CÚU}


Các yếu tố môi trường trong các hồ nước mặn

Trong 3 hồ nước mặn được khảo sát, 2 hồ (Áng Đầu Bê, Áng Quả Bàng) có cửa thông với biển và lượng nước trong hồ được trao đổi thường xuyên với môi trường biển bên ngoài thông qua sự chênh lệch của thủy triều và một hồ kín (Áng Dù) không có cửa thông với bên ngoài, nước ở đây được trao đổi rất hạn chế với bên ngoài thông qua các mao mạch hoặc các khe nứt nhỏ. Kết quả đo tại hiện trường và phân tích mẫu trong các hồ nước mặn qua qua đợt khảo sát vào tháng 7/2014 được trình bày qua bảng sau (bảng 1).

Bảng 1. Chất lượng môi trường nước trong các hồ nước mặn khu vực Hạ Long, Cát Bà

\begin{tabular}{|c|c|c|c|c|c|}
\hline TT & Thông số & Áng Dù & Áng Đầu Bê & Áng Quả Bàng & Giới hạn cho phép \\
\hline 1 & Nhiệt độ $\left({ }^{0} \mathrm{C}\right)$ & 29,0 & 32,1 & 30,9 & $30^{\circ} \mathrm{C}^{*}$ \\
\hline 2 & $\mathrm{DO}(\mathrm{mg} / \mathrm{l})$ & 8,64 & 9,03 & 7,63 & $\geq 5^{*}$ \\
\hline 3 & $\mathrm{pH}$ & 7,62 & 7,80 & 7,88 & $6,5-8,5^{*}$ \\
\hline 4 & Độ muối $(\%$ \%o $)$ & 9 & 24 & 23 & - \\
\hline 5 & Độ trong suốt (m) & 3,8 & 3,5 & - & - \\
\hline 6 & Nitrit $\left(\mathrm{N}-\mathrm{NO}_{2}{ }^{-}\right)(\mu \mathrm{g} / \mathrm{L})$ & 5,68 & 5,35 & 4,94 & $<10(\mu \mathrm{g} / \mathrm{L})^{* *}$ \\
\hline 7 & Nitrat $\left(\mathrm{N}-\mathrm{NO}_{3}{ }^{-}\right)(\mu \mathrm{g} / \mathrm{L})$ & 76,5 & 108,6 & 105,6 & $60(\mu \mathrm{g} / \mathrm{L})^{* * *}$ \\
\hline 8 & Amoni $\left(\mathrm{N}-\mathrm{NH}_{4}^{+}\right)(\mu \mathrm{g} / \mathrm{L})$ & 32,72 & 36,57 & 49,61 & $70(\mu \mathrm{g} / \mathrm{L})^{* * *}$ \\
\hline 9 & Phosphat $\left(\mathrm{P}-\mathrm{PO}_{4}{ }^{3-}\right)(\mu \mathrm{g} / \mathrm{L})$ & 15,84 & 17,92 & 18,00 & $15(\mu \mathrm{g} / \mathrm{L})^{* * *}$ \\
\hline 10 & $\mathrm{BOD}_{5}(\mathrm{mg} / \mathrm{l})$ & 1,08 & 1,02 & 0,96 & - \\
\hline 11 & $\operatorname{COD}(\mathrm{mg} / \mathrm{l})$ & 1,96 & 2,16 & 1,83 & $3(\mathrm{mg} / \mathrm{l})^{*}$ \\
\hline
\end{tabular}

Ghi chú: *: QCVN10: 2008/BTNMT; **: Bộ thủy sản; ***: Tiêu chuẩn ASEAN.

Môi trường nước trong các hồ nước mặn đã có biểu hiện của sự ô nhiễm khi so với quy chuẩn chất lượng nước biển ven bờ của Việt Nam (QCVN10: 2008/BTNMT) và tiêu chuẩn ASEAN. Điển hình là nhiệt độ nước trong hồ khá cao $\left(30,9^{\circ} \mathrm{C}\right.$ ở Áng Quả Bàng và $32,1^{0} \mathrm{C}$ ở Áng Đầu Bê) so với giới hạn cho phép đối với nước biển ven bờ là $30^{\circ} \mathrm{C}$. Điều đó cho thấy vào mùa hè (tháng 7) nhiệt độ trong các hồ khá nóng do nền nhiệt chung của mùa nóng cùng với sự bao quanh của các đảo đá vôi càng làm nhiệt độ nóng hơn và có thể đã ảnh hưởng đến đời sống của thủy sinh vật. Hàm lượng các chất dinh dưỡng như nitrat, phosphat trong các hồ đều cao hơn tiêu chuẩn của ASEAN, chứng tỏ có biểu hiện của sự phú dưỡng. Nguồn ô nhiễm cung cấp cho hồ từ bên ngoài vào thông qua dòng chảy qua các cửa thông với biển và từ lớp thảm mục của rừng cây trên đảo đá chảy xuống tích tụ trong lòng hồ.

Kết quả nghiên cứu còn thể hiện rõ sự khác biệt giữa các hồ là độ muối, trong hồ kín (Áng Dù) độ muối khá thấp $(9 \%$ ), trong khi hai hồ còn lại là $23 \%$ và $24 \%$. Điểu đó cho thấy vào tháng 7 là mùa mưa, lượng nước mưa trong hồ kín không được hoặc trao đổi hạn chế với môi trường bên ngoài dẫn đến độ muối trong hồ giảm xuống. Trong khi hai hồ còn lai nước được trao đồi thường xuyên nên độ muối tương đương với môi trường bên ngoài.

Theo nghiên cứu của Azzini Francesca (2007) [3] có sự phân tầng về độ muối và nhiệt độ ở hồ kín như Âng Dù. Vào mùa mưa độ muối thấp ở tầng trên với độ dày là $1,5 \mathrm{~m}$ trong khi mùa khô (tháng 4) sự phân tầng độ muối thẩp có độ dầy là $10-50 \mathrm{~cm}$. Sự phân tầng của nước đã ngăn cản sự đối lưu dẫn đến nhiệt độ ở tầng đáy đôi khi cao hơn ở tầng mặt từ $3-6^{\circ} \mathrm{C}$. Đây là hiện tượng bất thường trong hồ nước mặn.

\section{Các yếu tố môi trường trong các hang ngầm}

Các hang ngầm được khảo sát đều thông với các tùng áng hoặc hồ nước mặn ở đầu đôi diện nên nước được lưu thông thường xuyên theo sự lên xuống của thủy triều. Kết quả đo và phân tích các thông số môi trường nước trong các hang ngầm được thể hiện trong bảng 2 .

Các kết quả đo và phân tích các thông số môi trường nước trong các hang ngầm cũng tương tự như trong các hồ nước mặn, có một sồ 
thông số vượt quá giới hạn cho phép theo quy chuẩn Việt Nam và ASEAN. Trong đó, nhiệt độ trong các hang cũng đều vượt quá $30^{\circ} \mathrm{C}$. Điều này cho thấy thời điểm tiến hành khảo sát là thời gian nóng nhất trong năm nên nước trong vịnh nói chung và các tùng áng nói riêng khá cao dẫn đến nước trong các hang được lưu thông thường xuyên nên chúng có nhiệt độ tương đương với môi trường bên ngoài.
Hàm lượng nitrat và phosphat cao hơn tiêu chuẩn môi trường của ASEAN nhưng không có sự sai khác đáng kể giữa các hang ngầm và nước môi trường bên ngoài do tất cả các hang được khảo sát đều thông với môi trường bên ngoài và nước được lưu thông, trao đổi thường xuyên theo sự lên xuống của thủy triều.

Bảng 2. Chất lượng môi trường trong các hang ngầm khu vực Hạ Long, Cát Bà

\begin{tabular}{|c|c|c|c|c|c|}
\hline TT & Thông số & Hang Tối & Hang Sáng & Hang Quả Bàng & Giới hạn cho phép \\
\hline 1 & Nhiệt độ $\left({ }^{0} \mathrm{C}\right)$ & 30,7 & 31,4 & 30,6 & $30^{0} \mathrm{C}^{*}$ \\
\hline 2 & $\mathrm{DO}(\mathrm{mg} / \mathrm{l})$ & 7,05 & 6,50 & 8,40 & $\geq 5^{\star}$ \\
\hline 3 & $\mathrm{pH}$ & 7,30 & 7,80 & 7,80 & $6,5-8,5^{*}$ \\
\hline 4 & Độ muối $(\% 00)$ & 27 & 26 & 23 & \\
\hline 5 & Nitrit $\left(\mathrm{N}-\mathrm{NO}_{2}{ }^{-}\right)(\mu \mathrm{g} / \mathrm{L})$ & 6,35 & 7,19 & 6,93 & $<10(\mu \mathrm{g} / \mathrm{L})^{* *}$ \\
\hline 6 & Nitrat $\left(\mathrm{N}-\mathrm{NO}_{3}{ }^{-}\right)(\mu \mathrm{g} / \mathrm{L})$ & 114,3 & 82,7 & 97,9 & $60(\mu \mathrm{g} / \mathrm{L})^{* * *}$ \\
\hline 7 & Amoni $\left(\mathrm{N}-\mathrm{NH}_{4}^{+}\right)(\mu \mathrm{g} / \mathrm{L})$ & 58,33 & 39,08 & 45,85 & $70(\mu \mathrm{g} / \mathrm{L})^{* * *}$ \\
\hline 8 & Phosphat $\left(\mathrm{P}-\mathrm{PO}_{4}{ }^{3-}\right)(\mu \mathrm{g} / \mathrm{L})$ & 19,57 & 17,26 & 21,75 & $15(\mu \mathrm{g} / \mathrm{L})^{* * *}$ \\
\hline 9 & $\mathrm{BOD}_{5}(\mathrm{mg} / \mathrm{l})$ & 1,05 & 1,10 & 1,12 & - \\
\hline 10 & COD (mg/l) & 1,78 & 2,04 & 2,11 & $3(\mathrm{mg} / \mathrm{l})^{*}$ \\
\hline
\end{tabular}

Ghi chú: *: QCVN10: 2008/BTNMT; **: Bộ thủy sản; ***: Tiêu chuẩn ASEAN.

\section{Đa dạng sinh cảnh trong các hang ngầm và hồ nước mặn}

Kết quả khảo sát cho thấy, mặc dù các hang ngầm và hồ nước mặn thường có diện tích nhỏ nhưng chúng chứa một số sinh cảnh đặc thù, là nơi ẩn náu, trú ngụ của các loài sinh vật biển tạo ra sự đa dạng trong các hang ngầm và hồ nước mặn. Kết quả khảo sát đã xác định được 3 dạng sinh cảnh chính, đó là:

Sinh cảnh bãi đá, cuội sỏi: Chúng phân bố với diện tích nhỏ tại ven các Áng Đầu Bê, Áng Dù, Âng Quả Bàng và trong các hang ngầm. Khi triều kiệt để lộ ra các bãi đá tảng, đá cuội và sỏi - sạn. Sinh cảnh bãi đá trong các áng và hang ngầm đóng vai trò chủ đạo trong các hệ sinh thái tại khu vực này. Sinh vật phân bố ở sinh cảnh này rất phong phú, các loài động vật đáy bao gồm cua Charybdis (Charybdis) hellerii, Cù kì Myomenippe hardwickii, động vật thân mềm như ôc Cypraea scurra, Siphonaria sp., hàu biển Ostreidae sp., ốc nón Trochus pyramis, vẹm Perna viridis, sò biển Cardium multipunctatum .... Ngoài ra, còn có các loài da gai như hải sâm Holothuria
(Halodeima) atra, dưa chuột biển Heliocidaris crassispina, Cercodemas anceps. Đặc biệt tại Hang Tối, Hang Quả Bàng, san hô mềm Carijoa riisei phân bố diện tích lớn trên vách hang, nơi ảnh hưởng mạnh bởi thủy triều, ngoài ra còn có quần xã hải miên (Sponge) cũng rất phong phú.

Sinh cảnh bãi triều đá tại hồ nước mặn ít có sự phong phú và đa dạng về loài, bắt gặp chủ yếu là các loài động vật đáy như cua Charybdis (Charybdis) hellerii, ốc Cypraea scurra, Siphonaria sp., hàu biển Ostreidae. Các loài rong biển phân bố ở hệ sinh thái này bao gồm Aphanocapsa littoralis, Oscillatoria corallinaceae, Gigartina intermedia, Lobophora variegata.

Sinh cảnh bãi cát, cát bùn: Phân bố ở hồ nước mặn Áng Đầu Bê, Áng Quả Bàng, Hang Quả Bàng và Hang Tối. Nhìn chung, chúng có diện tích nhỏ ở các hang, do nước chảy thường xuyên nên bãi cát thường được tích tụ ở đáy hang với diện tích khoảng $5-10 \mathrm{~m}^{2}$ nhưng đôi khi tạo thành bãi khá dài trên $40 \mathrm{~m}$ ở cuối Hang Tối. Nền đáy cát bùn có ở Hang Quả Bàng do 
đoạn gần cửa hang khá rộng (trên $10 \mathrm{~m}$ ) trong khi phần còn lại có độ rộng 2 - $4 \mathrm{~m}$ nên nước chảy qua đoạn này chậm lại tạo sự tích tụ trầm tích bùn lẫn cát. Trong các hồ nước mặn loại sinh cảnh này lại chiếm diện tích khá lớn, chúng tạo thành bãi bao quanh như Áng Đầu Bê, Áng Quả Bàng ở độ sâu 0,5 - 2 m. Có nhiều sinh vật phân bố ở hệ sinh thái này như động vật thân mềm là sò Chlamys nobilis, sò Arca navicularis, sò Cardium multipunctatum, bàn mai Atrina pectinata, ngao Sanguinolaria maculosa, Marcia marmorata, Gafrarium divaricatum, sao biển Archaster typicus.

Sinh cảnh rạn san hô: Rạn san hô chỉ phân bố ở các hồ có nước trao đổi thường xuyên với biển như Áng Đầu Bê và Áng Quả Bàng. Áng Dù không có rạn san hô do nước có độ muối thấp, trong các hang không có rạn san hô do thiếu ánh sáng. Rạn san hô trong các hồ phân bố khá hẹp ở độ sâu 2 - 4 m, chúng tạo thành dải hẹp bao quanh vùng giữa hồ. Rạn san hô trong hồ cũng đang bị suy thoái thể hiện qua tỷ lệ đá san hô chết trên rạn khá cao trong khi tỷ lệ san hô sống thấp $10-25 \%$. Các nhóm loài san hô phổ biển trong hồ là san hô tổ ong Favia, san hô khối Porites, san hô phiến Pavona, san hô não Symphyllia, hay nhóm loài có xúc tu dài như Goniopora, Galaxea. Trên rạn có nhiều sinh vật sinh sống, đáng kể là động vật thân mềm như loài quéo Septifer bilocularis, vẹm Perna viridis, quắm Isognomon legumen, sò Cardium multipunctatum, bàn mai Atrina pectinata. Da gai phân bố chủ yếu ở hệ sinh thái này gồm loài cầu gai Diadema savignyi và Echinometra mathaei.

\section{Đa dạng loài sinh vật biển}

Cá: đã xác định được 14 loài cá biển thuộc 12 họ. Trong đó có 4 loài mới ghi nhận tại vùng biển Hạ Long - Cát Bà đó là loài cá Lethrinus nebulosus thuộc họ cá hè Lethrinidae, cá thia Abudefduf margariteus thuộc họ Pomacentridae, cá dìa Siganus sutor thuộc họ Siganidae, cá mù làn Scorpaenodes parvipinnis thuộc họ Scorpaenidae. Ớ Áng Đầu Bê có số lượng loài nhiều nhất là 6 loài, tiếp theo là hang Quả Bàng 5 loài, Hang Sáng 4 loài, các điểm còn lại có từ 1 - 2 loài. Các loài cá có giá trị kinh tế được tìm thấy trong các hang ngẩm và hồ nước mặn thuộc các giống cá đối $M u g i l$, cá bống Amblygobius, cá dìa Siganus, cá sơn Cheilodipterus, cá hồng Lutjanus, cá kìm Hemiramphus ...

Rong biển: đã ghi nhận được 12 loài rong biển thuộc 4 ngành trong các hồ nước mặn được khảo sát, trong đó ngành rong đỏ (Rhodophyta) có 4 loài, ngành rong nâu (Phaeophyta) có 3 loài, ngành rong lục (Chlorophyta) có 3 loài và ngành rong lam (Cyanophyta) có 2 loài. Mặc dù số loài phát hiện được không nhiều song hầu hết chúng đều có giá trị, trong đó có 5 loài có giá trị kinh tế (Polycavernosa fastigiata, Gigartina intermedia, Acanthophora orientalis, Caulerpa racemosa, Enteromorpha compressa), 7 loài có giá trị trong công nghiệp và y dược (Ceratodictyon spongiosum, Polycavernosa fastigiata, Gigartina intermedia, Dictyota linearis, Lobophora variegata, Padina boryana, Codium arabicum) và có 1 loài quý hiếm (Codium arabicum). Trong các hang ngầm đều không phát hiện thấy rong phân bố do điều kiện thiếu ánh sáng nên chúng không quang hợp được.

Hải miên: hải miên (Sponge) có 31 loài, thuộc 20 họ là Suberitidae, Phloeodictyidae, Aplysinidae, Tetillidae, Chalinidae, Clionaidae, Dictyonellidae, Dysideidae, Raspailiidae, Halichondriidae, Mycalidae, Ancorinidae, Petrosiidae, Suberitidae, Spongiidae, Tedaniidae, Tethyidae. Trong đó họ Halichondriidae có số loài nhiều nhất là 8 loài tiếp theo họ Clionaidae có 4 loài, họ Ancorinidae, Tethyidae, Suberitidae có 2 loài, các họ còn lại chỉ ghi nhận 1 loài. Số loài và họ hải miên ở hang ngầm và hồ nước mặn khá phong phú, tại Hang Tối có số loài nhiều nhất là 16 loài thuộc 12 họ, thấp nhất tại Hang Sáng và Hang Quả Bàng là 7 loài thuộc 7 họ. Các loài phân bố phổ biến là Aplysia sp., Cladocroce sp., Cliona celata, Spheciospongia solida, Haliclona (Haliclona) sp., Stelletta aruensis, Spongia irregularis, Tethya seychellensis, Xestospongia cf. testudinaria. Hải miên là nhóm phân bố phố biến và chiếm ưu thế trong các hang ngầm, chúng sống bám trên nền đáy đá hoặc trên vỏ của thân mềm hoặc cộng sinh với san hô sừng. Nhiều loài hải 
miên hiện đang được nghiên cứu chiết xuất các chất có hoạt tính sử dụng trong y dược.

San hô: Đã xác định được 53 loài san hô trong các hồ nước mặn và hang ngầm, trong đó nhóm san hô cứng có 41 loài chỉ sống ở hồ nước mặn và 12 loài san hô mềm sống chủ yếu trong các hang ngầm. Trong 3 hồ được nghiên cứu chỉ có 2 hồ có rạn san hô (Áng Đầu Bê và Áng Quả Bàng). Mặc dù san hô đã tạo thành rạn trong các hồ nước mặn, song diện tích không lớn, khoảng $500 \mathrm{~m}^{2}$ ở Áng Đầu Bê và $300 \mathrm{~m}^{2}$ ở Áng Quả Bàng. Tuy vậy san hô cũng vẫn giữ vai trò sinh thái quan trọng trong các hồ nước mặn, chúng tạo ra các hang hốc cho các sinh vật cư trú. Ở đây có các loài san hô dạng phiến như Pavona decussata, Echinopora lamellosa dạng cột trụ Goniopora columna, $G$. Lobata là nơi lý tưởng cho các loài cá rạn, thân mềm trú ngụ. Trong các hang ngầm nhóm san hô mềm cùng với hải miên là hai nhóm chủ đạo, tạo nên một quần xã đa dạng, đa sắc màu trong hang. Nghiên cứu này đã ghi nhận được quần thể san hô mềm Carijoa riisei ở Hang Tối và Hang Quả Bàng phát triển rất tốt, có nơi mật độ đạt $80 \%$ độ phủ, chúng bám trên các vách hang, trần và cả ở nền hang, thậm chí trên vỏ của thân mềm như hàu, hà, vẹm. Chúng phân bố tại cả những nơi không có ánh sáng, tạo thành những thảm lớn từ $1-5 \mathrm{~m}^{2}$.

Động vật đáy: Đã xác định được 32 loài thuộc 22 họ, thuộc các lớp giun nhiều tơ (Polychaeta), thân mềm (Mollusca), da gai (Echinodermata), giáp xác (Crustacea). Trong đó, động vật thân mềm có số loài nhiều nhất là 23 loài thuộc 13 họ, tiếp theo là da gai với 6 họ và 6 loài, giáp xác có 2 loài thuộc 2 họ, giun nhiều tơ có số loài thấp nhất là 1 loài.

Thành phần loài động vật đáy chủ yếu là các loài động vật thân mềm, trong đó các loài thuộc lớp chân bụng (Gastropoda) là 8 loài thuộc họ Buccinidae, Cerithidae, Thiaridae, Muridae, Trochidae, Naticidae. Các loài thuộc lớp hai mảnh vỏ Bivalvia có 14 loài, thuộc các họ Arcidae, Mytilidae, Pectinidae, Pteriidae, Cardiidae, Veneridae, Pinnidae. Trong đó, họ Ngao Veneridae có số loài nhiều nhất là 5 loài, họ có số loài ít nhất là Arcidae, Pectinidae và Pinnidae có 1 loài. Loài Septifer bilocularis và Isognomon isognomum phân bố phổ biến ở Áng
Đầu Bê, loài Perna viridis, Septifer bilocularis, Chlamys nobilis, Isognomon legumen phân bố phổ biến ở Hang Tối. Các loài ngao Cardium multipunctatum, Marcia marmorata, Arca navicularis, sò Chlamys nobilis, trai Pteria (Pinctada) martensii, bàn mai Atrina pectinata là các loài có giá trị thực phẩm và kinh tế cao nên đang bị khai thác và đánh bắt quá mức.

Các loài thuộc ngành da gai (Echinodermata) là 6 loài thuộc 6 họ, bao gốm sao biển năm cánh nhỏ Archaster typicus thuộc họ Archasteridae, loài cầu gai dài Diadema savignyi thuộc họ Diadematidae, cầu gai nhím Echinometra mathaei thuộc họ Echinometridae, cầu gai Heliocidaris crassispina thuộc họ Echinometridae, hải sâm đen Holothuria (Halodeima) atra thuộc họ Holothuriidae, dưa chuột biển Cercodemas anceps thuộc họ Cucumariidae. Các loài thuộc ngành da gai ở vùng biển Hạ Long và Cát Bà đang bị khai thác và đánh bắt quá mức, chúng là nguyên liệu của thực phẩm và dược liệu.

Ngành giáp xác (Crustacea) có hai loài gồm ghẹ Charybdis (Charybdis) hellerii thuộc họ Portunidae, cua cù kì Myomenippe hardwickii thuộc họ Menippidae. Trong đó loài cua cù kì Myomenippe hardwickii có giá trị cao về thực phẩm và kinh tế.

Lớp giun nhiều tơ phân bố ở các hang động và hồ nước mặn với số lượng loài rất ít, chỉ bắt gặp có 1 loài Clymenura tenuis thuộc họ Maldanidae.

Xét về cấu trúc quần xã động vật đáy ở hang động ngầm và hồ nước mặn cho thấy, quần xã giữ vai trò ưu thế là các loài động vật thân mềm cụ thể là quần xã các loài ốc và thân mềm hai mảnh vỏ như ngao, sò, bàn mai. Các loài là đối tượng hiện đang được khai thác như động vật thân mềm, cua, hải sâm, sao biển phân bố ở hầu hết các hang động và áng nước mặn. Do vậy, các quần xã khác có số loài ít, những loài có số loài trên họ là 1 - 2 loài thuộc nguy cơ bị biến mất, do gặp điều kiện bất lợi về môi trường hoặc do khai thác đánh bắt quá mức, các loài có giá trị thực phẩm và dược liệu đang bị suy giảm mạnh.

Sự đa dạng về thành phần loài sinh vật đáy ở các hang động ngầm và hồ nước mặn tại 
những địa điểm khác nhau có sự khác nhau đáng kể về số lượng loài. Tại Hang Tối có số loài động vật đáy nhiều nhất là 18 loài, tiếp theo tại Hang Quả Bàng có 11 loài, Áng Đầu Bê, Hang Sáng, Áng Quả Bàng có 6 loài, thấp nhất là tại Áng Dù có 3 loài.

\section{KẾT LUẬN}

Môi trường trong các hang động ngầm và hồ nước mặn có những đặc điểm tương đồng với môi trường bên ngoài (ngoại trừ hồ kín Áng Dù) do nước được lưu thông thường xuyên theo thủy triều. Đã có một số biểu hiện của sự ô nhiễm môi trường trong các hang ngầm và hồ nước mặn khi so sách với các quy chuẩn của Việt Nam và $A S E A N$, trong đó nhiệt độ, nitrat và phosphat đã vượt quá giới hạn cho phép. Trong hồ kín (Áng Dù) có sự phân tầng về độ muối và nhiệt độ làm nước tầng mặt và tầng đáy không trao đổi được dẫn đến hiện tượng bất thường là nhiệt độ tầng đáy cao hơn tầng mặt.

Đã xác định được 3 kiểu sinh cảnh trong các hang ngầm và hồ nước mặn là bãi đá - cuội sỏi, bãi cát - cát bùn và rạn san hô.

Quần xã sinh vật phổ biến trong các hang ngầm là hải miên và san hô mềm, chúng phân bố từ cửa hang đến những nơi tối hoàn toàn. Không phát hiện thấy có sự khác nhau về phân bố của các nhóm sinh vật theo độ sâu của hang, ngoại trừ nhóm rong và san hô cứng không có trong hang do không có ánh sáng. Đã xác định được 14 loài cá, 12 loài rong biển, 31 loài hải miền, 53 loài san hô, 1 loài giun nhiều tơ, 23 loài động vật thân mềm, 6 loài da gai, 2 loài giáp xác phân bố ở hang ngầm và hồ nước mặn. Trong đó có nhiều loài có giá trị kinh tế hoặc dùng trong các ngành công nghiệp chế biến, $\mathrm{y}$ dược. Đặc biệt trong nghiên cứu này, đã phát hiện được 4 loài cá bổ xung cho danh mục cá Hạ Long - Cát Bà. Không phát hiện được nhóm loài sống chuyên biệt trong các hang ngầm và hồ nước mặn.

Lời cảm ơn: Tập thể tác giả xin cảm ơn Nhiệm vụ hợp tác quốc tế mã số VAST.HTQT.Phap.03/13-14: "Môi trường và đa dạng sinh học trong các hang động ngầm và hồ nước mặn khu vực Hạ Long - Cát Bà", đã tài trợ kinh phí cho nghiên cứu này.

\section{TÀI LIỆU THAM KHẢO}

1. Trần Đức Thạnh, 2012. Kỳ quan địa chất vịnh Hạ Long. Tạp chí Các khoa học về Trái đất, 34(2): 162-167.

2. Cerrano, C., Azzini, F., Bavestrello, G., Calcinai, B., Pansini, M., Sarti, M., and Thung, D., 2006. Marine lakes of karst islands in $\mathrm{Ha}$ Long Bay (Vietnam). Chemistry and Ecology, 22(6): 489-500.

3. Azzini, F., Calcinai, B., Cerrano, C., Bavestrello, G., and Pansini, M., 2007. Sponges of the marine karst lakes and of the coast of the islands of Ha Long bay (North Vietnam). Custodia MR, LoboHajdu G, Hajdu E, Muricy G, Porifera research: Biodiversity innovation and sustainability. Rio de Janeiro, 157-164.

4. Gurjanova, E. F., and Phuong, C. H., 1972. Intertidal zone of the Tonkin Gulf. Journal of Exploration of the fauna of the sea, 10, 179-209.

5. English, S., Wilkinson, C., and Baker, V., 1997. Manual for survey of tropical marine resources $2^{\text {nd }}$ Edittion. $390 \mathrm{p}$.

6. Abbott, R. T., 1991. Seashells of Southeast Asia. Graham Brash. 145 p.

7. Abbott, R. T., and Dance, S. P., 1986. Compendium of Seashells. Melbourne, Florida: American Malacologists.

8. Böggemann, M., and Eibye-Jacobsen, D., 2002. The Glyceridae and Goniadidae (Annelida: Polychaeta) of the BIOSHELF Project, Andaman Sea, Thailand. Phuket Marine Biological Center, Special Publication, 24, 149-196.

9. Cernohorsky, W. O., 1972. Marine shells of the Pacific (Vol. 2). Pacific publications. $411 \mathrm{p}$.

10. Dance, S. P., 1997. Das grobe Bush der meer musheln: Schnecken und. Muscheln d. Weltmeer. Verlag Eugen Ulmer Stuttgart. 304 p.

11. Day, J. H., 1967. A Monograph on the Polycheata of Southern Africa. Part I: Errantia. $458 \mathrm{p}$

12. Day, J. H., 1967. A Monograph on the Polycheata of Southern Africa. Part II: Sedentantaria. $419 \mathrm{p}$ 
13. Fauchald, K., 1977. The polychaete worms; definitions and keys to the orders, families and genera. $188 \mathrm{p}$.

14. Fauvel, P., 1953. The Fauna of India including Pakistan, Ceylon, Burma and Malaya. Annelida Polychaeta. Allahabad, The Indian Press, 507 p.

15. Fitzhugh, K., 2002. Fan worm polychaetes (Sabellidae: Sabellinae) collected during the Thai-Danish BIOSHELF project. Phuket Marine Biological Center Special Publication, 24, 353-424.

16. Holthuis, L. B., Fransen, C. H., and Van Achterberg, C., 1993. The recent genera of the caridean and stenopodidean shrimps (Crustacea, Decapoda) with an appendix on the order Amphionidacea.

17. Imajima, M., 1972. Review of the annelid worms of the family Nereidae of Japan, with descriptions of five new species or subspecies. Publisher not Identified, 15, 37-153.

18. Morris, P. A., 1972. A Field Guide to shell of the Atlantic and Gulf Coasts and the West Indies. The Peterson Field Guide serise. Houghton Mifflin Company Voston. $330 \mathrm{p}$.

19. Snedaker, S. C., and Snedaker, J. G., 1984. The mangrove ecosystem: research methods. Unesco. p. 143-161.

20. Sakai, T., 1976. Crabs of Japan and the Adjacent Seas. Tokyo, Kodansha Ltd., pp xxix, pls.251.

21. Turner, R. D., and Boss, K. J., 1962. The genus Lithophaga in the western Atlantic. Department of Mollusks, Museum of Comparative Zoölogy, Harvard University.

22. Cernohorsky, W. O., 1972. Marine shells of the Pacific (Vol. 2). Pacific publications. $411 \mathrm{p}$.

23. Gallardo, V. A., 1968. Polychaeta from the Bay of Nha Trang, South Viet Nam. Scripps Institution of Oceanography.

24. Veron, J. J., and Pichon, M. M., 1976. Scleractinia of eastern Australia. Part I: Families Thamnasteriidae, Astrocoeniidae, Pocilloporidae. 1, 1-86.
25. Veron, J. E. N., and Pichon, M. WijsmanBest, M., 1977. Scleractinia of eastern Australia. Part II. Families Faviidae, Trachyphyliidea. Australian Institute of Marine Science Monograph Series, 3, 1-233.

26. Veron, J. J., and Pichon, M. M., 1980. Scleractinia of Eastern Australia. Part III: Families Agariciidae, Siderastreidae, Fungiidae, Oculinidae, Merulinudae, Mussidae, Pectiniidae, Caryophylliidae, Dendrophylliidae. 4, 1-422.

27. Veron, J. J., and Pichon, M. M., 1982. Scleractinia of eastern Australia. Part IV: Family Poritidae. 5, 1-159.

28. Veron, J. E. N., and Wallace, C. C., 1984. Scleractinia of Eastern Australia. Part V Families Acroporidae. Australia Institute Marine Science Monogr. Ser. 6, 1-485

29. Veron, J. E. N., 1986. Corals of Australia and the Indo-Pacific (p. 490). Angus \& Robertson.

30. Veron, J. E. N., 2000. Corals of the World. Vol. 1-3. Australian Institute of Marine Science, Townsville.

31. Nguyễn Hũu Dinh, Huỳnh Quang Năng, Trần Ngoc Bút, Nguyê̂n Văn Tiên, 1993. Rong biển Việt Nam (phần phía Bắc). Nxb. Khoa học và Kỹ thuật, Hà Nội. 364 tr.

32. Phạm Hoàng Hộ, 1969. Rong biển Việt Nam (phần phía Nam). Trung tâm học liệu Sài Gòn. 558 tr.

33. Bowerbank, J. S., 1869, January. A Monograph of the Siliceo-fibrous Sponges. In Proceedings of the Zoological Society of London (Vol. 37, No. 1, pp. 66-100). Blackwell Publishing Ltd.

34. Bowerbank, J. S., 1869, January. A Monograph of the Siliceo-fibrous Sponges. In Proceedings of the Zoological Society of London (Vol. 37, No. 1, pp. 323-351). Blackwell Publishing Ltd.

35. Beaufort, L. F., 1994. The Fishs of the Indo-Australian. Vol 8. pp. 16-323.

36. Beaufort, L. F., 1994. The Fishs of the Indo-Australian. Vol 9. pp. 1-393.

37. Eschmeyer, W. N., 1998. Catalog of fishes. 
38. Carcasson, $R$. H., 1977. A field guide to the coral reef fishes of the Indian and West
Pacific Ocean.

\title{
NEW DATA ON WATER ENVIRONMENT AND ORGANISM IN SUBMERGED CAVES AND SALTWATER LAKES IN HA LONG AND CAT BA AREAS
}

\author{
Nguyen Dang Ngai, Dau Van Thao, Do Cong Thung, Le Thi Thuy, Pham Van Luong, \\ Cao Thu Trang, Vu Thi Luu, Dam Duc Tien, Nguyen Van Quan, Pham Van Chien
}

Institute of Marine Environment and Resources-VAST

\begin{abstract}
Submerged caves and saltwater lakes are 2 common habitat types in Ha Long and Cat Ba. However, depending on many different reasons so far they have been poorly studied both on environmental and biological characteristics. The initial results on environment and biological communities in 3 submerged caves (Hang Sang, Hang Toi, Qua Bang) and 3 saltwater lakes (Ang Dau Be, Ang Du, Ang Qua Bang) showed that: status of water environment was different among lakes, especially in the closed lake as Ang Du where salinity was low (9\%o), while salinity in the lakes connected to the sea was equal to marine environment (23-27\%o). Concentration of dissolved oxygen (DO) in saltwater lakes was high from $7.63-9.03 \mathrm{mg} / \mathrm{L}$ and higher than that in submerged caves and surrounding marine environment. Physical and chemical factors of water in the submerged caves were equivalent to the marine environment because these caves are connected to the sea and water regularly goes in and out according to tidal fluctuation. Organism communities in the submerged caves were abundant with over 142 species being found. The popular groups, sponge and soft coral, were distributed along the length of the caves. Several species with high economic value were commonly observed in the caves, including stone crab Myomenippe hardwickii, flower crab Portunus pelagicus, cone snails Trochus pyramis, shoemaker spinefoot Siganus sutor, snapper Lutjanus russelii ... Species that permanently live in cave were not detected. In the lakes where water is well exchanged to the sea, coral reefs were found and they formed a narrow reef around the lake. Sandy bars often appeared around the lake at the depth of $0.5-2 \mathrm{~m}$, containing specialty species as phi (Sanguinolaria diphos), snout otter clam (Lutraria rhynchaena), sea cucumbers with high density (Ang Dau Be, Ang Qua Bang). There was no coral reef in the closed lake (Ang Du) because of low salinity. In this lake, stratification of temperature and salinity led to temperature on surface lower than that on bottom from $3^{\circ} \mathrm{C}$ to $6^{\circ} \mathrm{C}$, this phenomenon is unusual.
\end{abstract}

Keywords: Submerged caves, saltwater lakes, biodiversity, environment. 